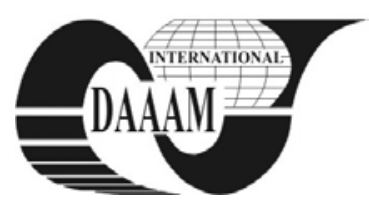

Annals of DAAAM for 2011 \& Proceedings of the 22nd International DAAAM Symposium, Volume 22, No. 1, ISSN 1726-9679 ISBN 978-3-901509-83-4, Editor B. Katalinic, Published by DAAAM International, Vienna, Austria, EU, 2011 Make Harmony between Technology and Nature, and Your Mind will Fly Free as a Bird Annals \& Proceedings of DAAAM International 2011

\title{
MODULES OF MUSIC LEARNING MANAGEMENT SYSTEM
}

\author{
SLOVAK, D[alibor] \& LATAL, P[etr]
}

\begin{abstract}
Music learning management system was developed as a web-based support for teaching music theory. In the previous article we informed you about this music learning management system. This article is aimed to refer about all developed modules for the MLMS. We established the data-base structure of authors, music genres and music samples. It was necessary to create administration system where will be the teacher able to form the music staves and present them on the web portal. Everything is connected with the learning portal, which allows students to register, to apply for entry into the classes, receive the information, training and test their knowledge through the test module.
\end{abstract}

Key words: content management system modules, music stave generator, quiz generator

\section{INTRODUCTION}

Music learning management system (in brief "MLMS") is being developed as solution for teaching music theory in modern way. In previous article we described the basic functions and communications of the portal and now we would like to describe all featured modules of the portal with fully outlined parts of each function.

\section{MODULES}

All modules are created exactly for learning portal and correspond with author's idea of music learning management system.

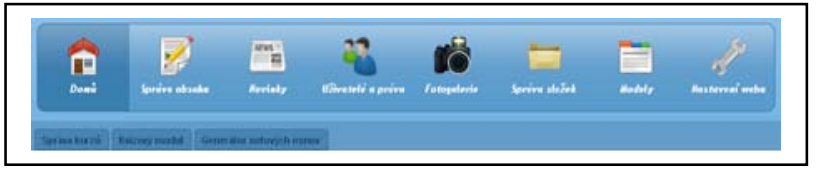

Fig. 1. Basic modules panel in administration

\subsection{News module}

The module acts as a simple interface for adding new products to the main page of the site. It works with actions such as adding news, editing news and deletion of the news. It is important to choose the language equally as in the content module, name, dates and text news. The validation script will call you for the revalidation when you not complete all the boxes prompted. Date of news is facilitated by the simple jQuery calendar, which can easily offer current date listing of the months and years by clicking in the text area. The output data format is similar to the syntax of SQL function now (), so the work with date is very comfortable in system back-end.

\subsection{Users and rights}

Users of the system are an integral part of the distribution system management roles. Here you can find ordinary users who have been registered on the web site and users inserted to the system as the system administrators. Users are simply categorized in the group. Module contains tab with the current distribution of groups in database. Each group has assigned value. This value means that if the user has higher value, he has higher permissions with access. For example the group named super admin has value 3 so this user can access anywhere. Group named administrators have value 2 so this user cannot access to the modules management.

Authorized user can easily edit and assign different rights to another user. Module offer editing such as the password change and some changes of the user access and all the personal information.

\subsection{Photo gallery module}

Photo gallery module was created for fast adding of images and integration to the system. This module is connected to the module "folder administration," because of each image classification. If you do not create the folder tree, you can upload all the photos into one folder, but this may result in bad output on the web. Each photo is re-editable, erasable and can be edited directly on the server. Paging module is implicitly set to 30 images on the page, but this value can be changed in the system. Adding photos is a very simple and powered by link "Add photo". You just fill out the category name, description of photos and choose a photo from the local computer.

\subsection{Folder administration module}

This is a very strategic module of the system. Each part of the site is categorized in some way. System will upload photos, videos, or link different modules (eg "quiz module" or "course module") depending on the created folder structure. Folder administration database is the distribution of different types of web content. Adding of the new components is performed by the link "add folder" and again it is important to select the category to the new folder and select the language.

\subsection{Managing modules}

This is the most important module in the system. User should have to connect each module with the database and system very carefully. Fill in the wrong arguments could threaten the stability of the system. The main page of the module shows only active modules in the right corner, but you can see the all modules or only the active or inactive modules by choosing in select box. Each module has action module. These actions mean query from the administration to add, edit or view any module.Each action of the module has checked permissions in the database so any user cannot access, display or edit module without permissions.

\subsubsection{The procedure for creating the new module}

Create folder for example: "testmodul" on the server in the directory /inc/admin/. Create files upravy.php, hlasky.php in this folder. Then create files testadd.php for adding content, testedit.php for editing content and manage_test.php for an overview. This created structure is needed to be linked with the system. Each module is quite complex so the new user does not immediately know how to fill form. For these purposes, each item is described and user should have problems with fill in 
necessary fields. For each module you can create "alias". This option was created for the easy administration of any tab. It gives possibility to add alias for any module in any tab fully associated with given module. These modules are marked with the star in modules manager.

\subsection{Site settings}

This is essentially the language module that is used to modify the language simple layout via the web interface in administration. We are able to add a new cell to the database with properties that can then be applied anywhere on the web by the sophistication of this module. Items are categorized as the data type, date and name of the item. The item ID cell is displayed only and cannot be edited because of identifier which contains necessary information for modification in database.

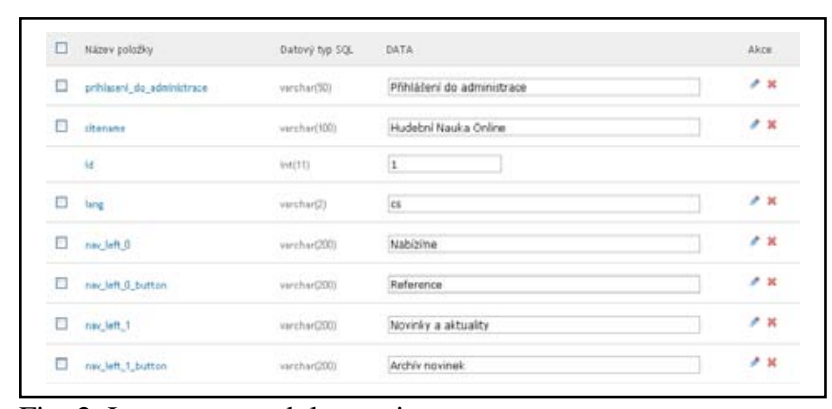

Fig. 2. Language module preview

Adding of the new item is performed by the link "Add lang item" and offers a brief with features such as the data type, name without diacritics and save button to insert new item to the database. After inserting you can set the value of the item.

\subsection{Courses management}

This module has similar module components to file management module, because you can create independent tree structure of courses. Each course contains a name, description of the course, password for the course and course leader. It is possible to set whether the course is active or not. In the list of courses is the list of registered students and the course leader. To see the all students named in the course, just click on the link named registered students. If you want to add student to the list, just add him using the "add user" link. In the point of course creation is necessary to select the right category, write the name of the course than create a password for the course and associate it with head of the course. It would be good to create a short description of the course, which will be displayed on the site and will serve as information for candidates. In the head of course is possible to choose registered users from select box. If the user does not exist, it is necessary to create him in the module "Users and rights" and then add him the appropriate permissions.

\subsection{Stave generator}

Module for generating staves is served as the simplified interface for creating musical staves for the quiz module and for the presentation of given expressions on the web. The main features of the module include the name of the stave, connection with the test and stave status.

From the database perspective the module contains a data section, which is generated by module and stored in a database as a complete code ready for presentation.

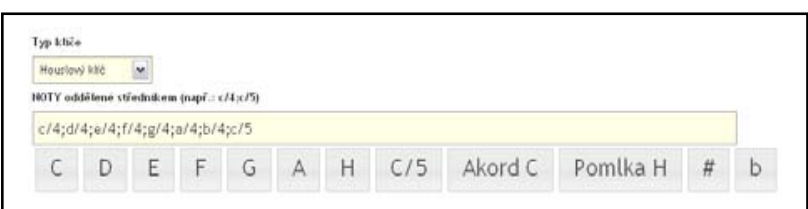

Fig. 3. Stave generator module preview

\subsection{Quiz module}

This is the module that generates any types of quiz or test. The basic properties of this module are the name of the quiz results, categories, and the basic operations such as editing, adding and deleting quizzes. For each quiz you can take a look at the results of every student who completed the quiz. There is a visible success, the date of attempt and the answers structure of the student.

\subsubsection{New quiz creation}

Creation of the quiz is divided into two steps. The first step is the selection of the number of questions and the number of responses. Here is a good to decide the good number of questions and answers, because if you change your mind the number of questions or the number of answers you have to regenerate the form. In this situation is the best solution to save the quiz and then edit it because editing will not lost the actual data. In the second step is "Quiz generation." The module will now expand to the right side. Here is necessary to fill in the quiz name, category, set number of attempts and select status of the quiz. When you generate the quiz, the interface will appear box for adding questions with answers. You can simply fill in your questions with answers. Because the questions and answers are over dimensioned, it is necessary to modify a few items. The first item is the type of answers. This offers the text type, radio and the checkbox. Changing any type will display the form of answers. Selecting musical stave from the select box will display chosen stave. Please refer to the fact that each question has to have different stave (or stave with another identifier).

\section{CONCLUSION}

The aim of this article was to describe the all features and modules of the MLMS. System has various kinds of modules connected together. Administrator can manage, create and edit all the contents of the portal, manage users and rights, quizzes and musical stave generator and many other modules. Administrator requires just a basic knowledge of music theory. There is required only the syntax for writing the music staves which can be connected with quiz module and presented on the web portal. Management is fully featured with the multilanguage administration, so administrators can easily manage any module in any language.

This was the second article from four which we wanted to describe. In the next article we should show the VexFlow core of the system with small tutorial how it works in real. And in the final article will be described front-end site of the portal with all features.

\section{REFERENCES}

Castro, Elizabeth (2007). HTML : XHTML a CSS: web site creating. Computer Press, ISBN 978-80-251-1531-2, Brno.

Composite authors (2007), PHP 5 mastery, Computer Press, ISBN 978-80-251-1519-0, Brno.

Henk C.A : van TILBORG (2000). Fundamentals of cryptology, Kluwer Academic, ISBN 0-7923-8675-2, Norwell.

Resig, John (2007). Javascript a AJAX : modern programming of web applications, Computer Press, ISBN 978-80-2511824-5, Brno.

Resig, John. (2007) Javascript a AJAX : Moderní programování webových aplikací. Computer Press, ISBN 978-80-251-1824-5. Brno.

Schlossnagle, Georgie (2004). PHP 5 advanced programming, Computer Press, ISBN 80-86815-14-5, Brno.

Zelinka, Ivan. (1999). Applied informatics, Editorial center, UTB, . ISBN 80-214-1423-5, Zlin 